\title{
Acid Modified Jourdiqua Clay for Methanolysis of Castor Oil
}

Abdul Rahim Yacob*, Ahmed Mahgoub Saied Mohmedahmed, Muhammad Azam bin and Muhammad Zaki

${ }^{*}$ Department of Chemistry, Faculty of Science, University Teknologi Malaysia, UTM Skudai, Malaysia

*Corresponding author: Abdul Rahim Yacob, Department of Chemistry, Faculty of Science, University Teknologi Malaysia, UTM Skudai, Malaysia, Tel: (60) 137428830; E-mail: manrahim@kimia.fs.utm.my

Received date: Sep 13, 2017; Accepted date: Sep 27, 2017; Published date: Oct 04, 2017

Copyright: (C) 2017 Yacob AR, et al. This is an open-access article distributed under the terms of the Creative Commons Attribution License, which permits unrestricted use, distribution, and reproduction in any medium, provided the original author and source are credited.

\begin{abstract}
Clay and clay minerals have very promising future in catalysis of chemical reactions. In this work Jourdiqua clay from north of Sudan was acid modified and used as heterogeneous catalyst in transesterification reaction of castor oil with methanol. The clay was modified with hydrochloric acid, $\mathrm{HCl}$. at $30 \%, 40 \%, 50 \%, 60 \%$ and $70 \%$ weight concentration with respect to the clay, respectively. The raw and acid modified clay were characterized by Fourier transform infrared analysis (FTIR), field emission electron microscope (FESEM), back titration, TPD-NH3 technique and nitrogen adsorption desorption (BET) analysis, to determine the physico-chemical properties and the acidity of the raw and modified clay. The surface area and active sites of the modified clays were found to increase with the acid treatment. Transesterification of castor oil with methanol were done under the reaction condition of $9 \% \mathrm{w} / \mathrm{w}$ catalyst loading, methanol to oil molar ratio of $18: 1,3 \mathrm{~h}$ reaction time and the reaction temperature of $67^{\circ} \mathrm{C}$. The biodiesel yield was monitored using nuclear magnetic resonance ${ }^{1} \mathrm{HNMR}$ spectroscopy. The highest conversion observed is $83.86 \%$ achieved by $50 \% \mathrm{HCl} /$ Clay.
\end{abstract}

Keywords: Jourdiqua Clay; Biodiesel; Transesterification; Heterogeneous; Catalyst

\section{Introduction}

Biodiesel is the methyl esters of fatty acids develop as an alternative to fossil fuels. The strongest motivation factor is the concern about global pollutant. Biodiesel has many environmental benefits, which include less greenhouse effect, less air and soil pollution, leading to less health risk. Today, over 85 biodiesel production plants are working worldwide. Biodiesel is produced by transesterification of triglycerides or from the esterification of fatty acids, both with a short chain alcohol such as ethanol or methanol in the presence of acid or base catalyst [1].

In recent years, the development of alternative fuel like bioethanol and biodiesel from renewable sources has received considerable attention. Homogeneous catalysts are used but they have problems such as leaching, require washing and this cause saponification and release of wastewater. Heterogeneous solid catalysts such as zeolites and clay minerals have been developed as substitutes to homogeneous catalysts and have benefit of being easy to recover and the process does not require washing.

Clays are promising catalyst especially after modification with acids or bases. Clays normally are hydrated aluminum silicate with very fine particle size usually less than $2 \mu \mathrm{m}$ with layered structure formed by tetrahedral sheets linked to an octahedral sheet through sharing of apical oxygen. The best known clay minerals are the smectite group that are widely used in various branches of industries due to their high cation exchange capacity, swelling ability and high surface area [2].

It is very important to find cheap raw materials without competition with arable land and food for the development of biofuel, such as nonedible oil, waste oil and fats. Castor oil is a very promising source for biodiesel. It is colourless or pale yellowish oil extracted from seeds of castor oil plant. Castor (Ricinus communis $\mathrm{L}$ ) is cultivated around the world because of the commercial importance of its oil, which is used in the manufacture of a number of industrial chemicals like surfactants, grease, lubricants, soap, surface coating and cosmetics. Castor seed has an oil content of $42 \%$ to $48 \%$. Castor plant grows well under hot and humid tropical conditions and has a growing period of 4 months to 5 months. Castor oil has density of $950 \mathrm{~kg} / \mathrm{m} 3$ at $15^{\circ} \mathrm{C}$, and molecular weight of $927 \mathrm{~g} / \mathrm{mol}$. The main fatty acid present in castor oil is ricinoleic acid with percentage of about $90 \%$ [3].

The aim of this study is to produce biodiesel from vegetable oil (castor oil) using clays as acid catalyst after modification with hydrochloric acid. Therefore in this work, Jourdiqua clay was brought from north of Sudan at the shore of River Nile to be used as acid modified heterogeneous catalyst in the transesterification reaction between castor oil and methanol.

\section{Experimental}

\section{Reagents and materials}

The starting clay samples are natural Sudanese clays, Jourdiqua (black clay) from north of Sudan. Castor oil was purchased from local shop. Methanol of purity 99\%, hydrochloric acid 37\% (w/w) and potassium hydroxide were obtained from Aldrich. Deionized water was used for the preparation of solution. All chemicals are of analytical grade and used without further purification. The clay samples were dried in an oven at $80^{\circ} \mathrm{C}$ overnight. After that, it was grinded and sieved through 200 mesh $(75 \mu)$ sieve to obtain Ca $0.075 \mathrm{~mm}$ particle size, and kept in sample bottles.

\section{Preparation of the catalysts}

About $100 \mathrm{~g}$ of Jourdiqua clay were calcined at $450^{\circ} \mathrm{C}$ for $4 \mathrm{~h}$ then cooled in a desiccator, $10 \mathrm{~g}$ of the raw Jourdiqua clay was weighed and transferred into each of six different $250 \mathrm{~mL}$ double neck round bottom flask in order to prepare solutions of different $\mathrm{HCl}$ concentrations, followed by addition of $100 \mathrm{~mL}$ of $0 \%, 30 \%, 40 \%, 50 \%$, 
$60 \%$ and $70 \%$ weight concentration of $\mathrm{HCl}$ solutions. The mixture was refluxed at $90^{\circ} \mathrm{C}$ under stirring at $300 \mathrm{rpm}$ for $3 \mathrm{~h}$. The mixtures were cool to room temperature, then filtered and washed with distilled water. The samples were finally dried in an oven at $80^{\circ} \mathrm{C}$ overnight. The clay samples are denoted; $0 \% \mathrm{HCl} / \mathrm{Clay} 30 \% \mathrm{HCl} /$ Clay, $40 \% \mathrm{HCl} / \mathrm{Clay}$, $50 \% \mathrm{HCl} / \mathrm{Clay}, 60 \% \mathrm{HCl} / \mathrm{Clay}$ and $70 \% \mathrm{HCl} /$ Clay for Jourdiqua and acid modified samples using, $0 \%, 30 \%, 40 \%, 50 \%, 60 \%$ and $70 \%$ weight concentration of $\mathrm{HCl}$ respectively.

\section{Characterization of acid modified clay}

All of the prepared catalyst were labelled and characterized by using, Fourier transform infrared spectroscopy (FTIR), X-ray Diffraction (XRD), Brunauer-Emmet-Teller (BET) and temperature programmed desorption for base (NH3-TPD).

\section{Transesterification of castor oil with methanol}

The Transesterification reaction of the castor oil was conducted, using the raw and modified clays in $250 \mathrm{ml}$ double neck round bottom flask with methanol to oil molar ratio of $18: 1$, catalyst loading $9 \%$, reaction time of $3 \mathrm{~h}$ at $67^{\circ} \mathrm{C}$, under stirring at $300 \mathrm{rpm}$. After completion of the reaction the products are allowed to settle overnight and centrifuged at $3000 \mathrm{rpm}$ for $15 \mathrm{~min}$. Three layers were observed; upper layer of methanol was distilled, while the middle layer of biodiesel and the lower layer of glycerol and settled catalyst were separated using separation funnel. Biodiesel was dried and then characterized by ${ }^{1} \mathrm{HNMR}$ technique [4].

\section{Results and Discussion}

\section{Fourier transform infrared analysis (FTIR)}

The infrared spectra of raw Jourdiqua clay and acid modified clay are as shown in Figure 1.

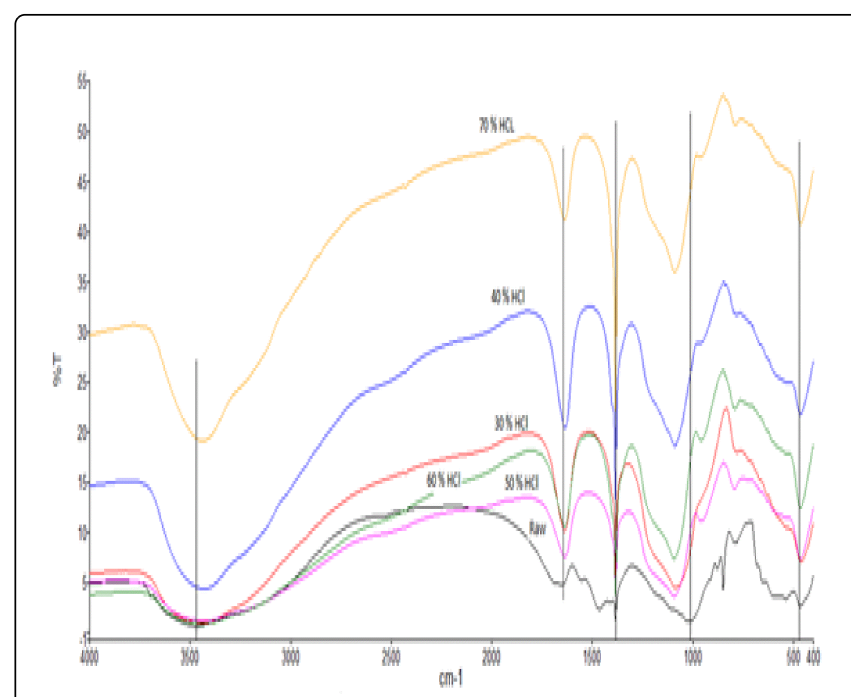

Figure 1: FTIR spectra of raw and acid modified Jourdiqua clay with $30 \%, 40 \%, 50 \%, 60 \%$ and $70 \% \mathrm{HCl}$.

The FTIR spectra for raw Jourdiqua clay and acid modified Jourdiqua clay displayed similar characteristic peaks, which are at 3483 $\mathrm{cm}^{-1}$ indicating the stretching vibration of $\mathrm{OH}$ group of clay structure.
The absorption band at $1607 \mathrm{~cm}^{-1}$ which is due to the $\mathrm{OH}$ deformation of water. The presence of silica is confirmed from the absorption peaks at $1174 \mathrm{~cm}^{-1}$ and $1024 \mathrm{~cm}^{-1}$ that is correspond to $\mathrm{Si}-\mathrm{O}$ stretching vibration and band at 498 for Si-O-Si deformation, it was observed that the most of the bands were shifted to the lower wavenumber after acid modification.

\section{Acid sites concentration by back titration}

The acid sites concentration of raw and modified clay was determined by back titration method. Figure 2 shows the amount of acid sites for raw Jourdiqua clay and Jourdiqua clay modified with $30 \%$ $\mathrm{HCl}, 40 \% \mathrm{HCl}, 50 \% \mathrm{HCl}, 60 \% \mathrm{HCl}$ and $70 \% \mathrm{HCl}$. Raw Jourdiqua clay shows the acid sites concentration of $0 \mathrm{mmol} / \mathrm{g}$. This is due to the presence of plenty amount of sodium carbonates and sodium bicarbonates $\left(\mathrm{Na}_{2} \mathrm{CO}_{3}\right.$ and $\left.\mathrm{NaHCO}_{3}\right)$ in the natural clay. After the Jourdiqua clay was modified with $30 \% \mathrm{HCl}, 40 \% \mathrm{HCl}, 50 \% \mathrm{HCl}, 60 \%$ $\mathrm{HCl}$ and $70 \% \mathrm{HCl}$, it shown that, the acid sites concentration increase to $1.2670,3.2550,5.3782,4.2158$ and $2.7152 \mathrm{mmol} / \mathrm{g}$ respectively. This is because during acid treatment, ion exchange process took place and the protons replaced the cations between clay layers. Thus, the acidity of modified clay increased with increasing acid concentration used, to the certain limit, from $30 \%(1.2670 \mathrm{mmol} / \mathrm{g})$ up to $50 \%(5.3782$ mmole/g). After that, the acidity start to decrease with increasing acid concentration, acid sites for $60 \%$ and $70 \%$ are $4.2158 \mathrm{mmol} / \mathrm{g}, 2.7152$ $\mathrm{mmol} / \mathrm{g}$ respectively. This reduction in acidity occurred when high concentration of acid was used, due to the fact that octahedral $\mathrm{Al}^{3+}$ cations were removed which results in the formation of silanol groups and thus decreasing the acidity of the catalyst [5]. Based on the back titration analysis, $50 \% \mathrm{HCl} /$ clay gives the highest acid site. Thus, only $50 \% \mathrm{HCl} /$ clay will be used for further analysis.

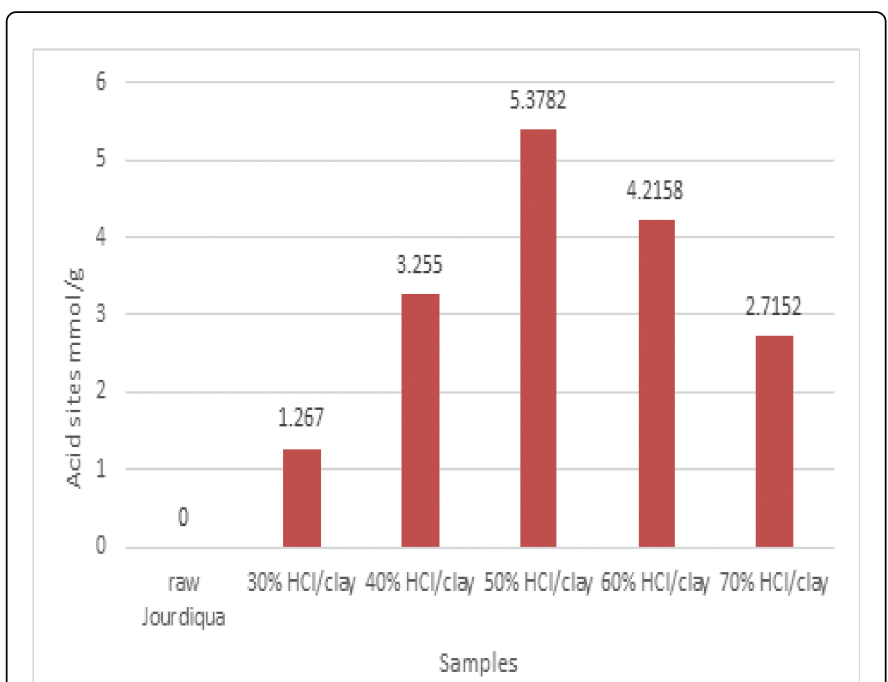

Figure 2: Concentrations of acidic sites for Jourdiqua clay treated with different loading of $\mathrm{HCl}$.

\section{Temperature programmed desorption (NH3-tpd)}

Acid sites measurements were carried out via thermal programmed desorption (TPD) of $\mathrm{NH} 3$. In the temperature ranged from $50^{\circ} \mathrm{C}$ to $800^{\circ} \mathrm{C}$, using nitrogen as the carrier gas. The strength distribution of the acid was estimated by TPD pattern deconvolation. Two catalysts, 
Citation: Yacob AR, Mohmedahmed AMS, Azam bin M, Zaki M (2017) Acid Modified Jourdiqua Clay for Methanolysis of Castor Oil. J

Page 3 of 5

$30 \% \mathrm{HCl} /$ clay and $50 \% \mathrm{HCl} /$ clay were used for TPD technique to reveal the amount and strength of acidic sites in the catalysts. The profile for the two catalysts is shown in Figure 3. It was observed that $30 \% \mathrm{HCl} /$ clay in (red) has three peaks for acidic distribution; the first peak is at $93.7^{\circ} \mathrm{C}$, which is considered to be weak site with a value of $0.4576 \mathrm{mmol} / \mathrm{g}$. The second peak is at $660.3^{\circ} \mathrm{C}$, which is classified as strong site with value of $0.6677 \mathrm{mmol} / \mathrm{g}$. Third peak appeared at $793.4^{\circ} \mathrm{C}$ and it is considered to be strong site with a value of 0.1416 $\mathrm{mmol} / \mathrm{g}$. The total acidity of the catalyst is the sum of the three sites concentration which is $1.2670 \mathrm{mmol} / \mathrm{g}$.

$50 \% \mathrm{HCl} /$ clay in (black), illustrate four characteristic peaks. First peak being at $612.4^{\circ} \mathrm{C}$, which is strong acidic site with value of 2.8433 $\mathrm{mmol} / \mathrm{g}$. Second peak appeared at $700.7^{\circ} \mathrm{C}$, which is also considered as strong site with value of $2.3653 \mathrm{mmol} / \mathrm{g}$. The third peak appeared at $784.6^{\circ} \mathrm{C}$, which is a strong site with a value of $0.11567 \mathrm{mmol} / \mathrm{g}$. while the last peak appeared at $794.8^{\circ} \mathrm{C}$ with a value of $0.05382 \mathrm{mmol} / \mathrm{g}$ that is a strong site. The $50 \% \mathrm{HCl} /$ clay catalyst has a total acidity of 5.3782 $\mathrm{mmol} / \mathrm{g}$. This result reconfirms the back titration analysis.

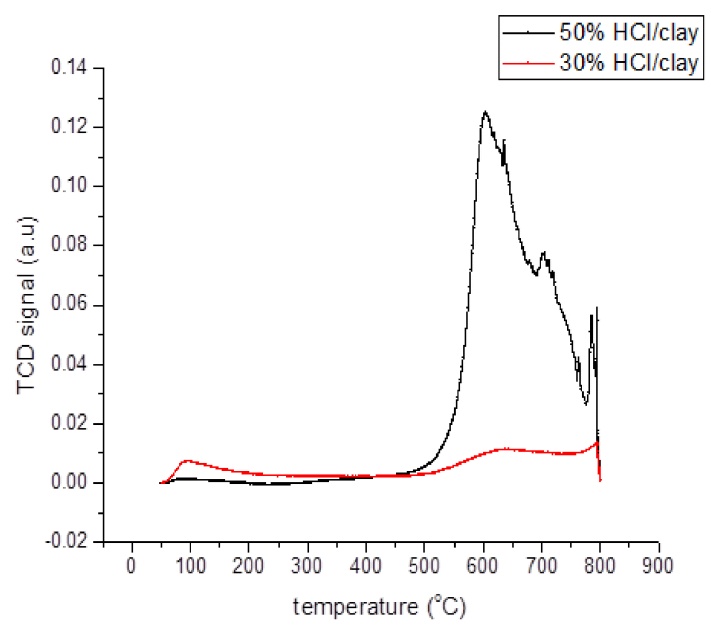

Figure 3: Distribution of acid sites for $30 \% \mathrm{HCl} /$ clay and $50 \% \mathrm{HCl} /$ clay.

\section{Field emission scanning electron microscopy (FESEM)}

The morphology and approximate particle size of the samples were examined using FESEM analysis. Figure 4 shows FESEM images at magnification of 10000 times of raw Jourdiqua clay and 50\% $\mathrm{HCl} /$ Clay respectively. It can be observed from the micrograph that raw Jourdiqua clays shows a flaky particles shape which is the characteristic of montmorillonite clay with particle size ranging from $0.5 \mu \mathrm{m}$ to 5.00 $\mu \mathrm{m}$ [6]. After the modification of Jourdiqua clay with $50 \% \mathrm{HCl}$, the morphology of the clay changed from larger layers to fragments pieces. Acid modified clays are arranged in needle like shape with particles sizes of $50 \mathrm{~nm}$ to $100 \mathrm{~nm}$ in width and of $0.25 \mu \mathrm{m}$ to $1.00 \mu \mathrm{m}$ in length. EDX analysis indicates the reduction percentage of some cations in the clay due to their elimination by the acid. EDX elemental analysis of raw Jourdiqua clay and $50 \% \mathrm{HCl} / \mathrm{Clay}$ are shown in Table 1 . It shows that raw Jourdiqua clay contains many cations such as $\mathrm{Na}, \mathrm{K}, \mathrm{Ca}, \mathrm{Fe}$ and $\mathrm{Mg}$. While $50 \% \mathrm{HCl} / \mathrm{Clay}$ shows that base treatment, reduce some of the cations.

\begin{tabular}{|l|l|l|}
\hline \multirow{2}{*}{ Element } & Mass $\%$ & $\mathbf{5 0 \%}$ HCI/Clay \\
\cline { 2 - 3 } & Raw Jourdiqua & 69.5 \\
\hline Silicon & 6.03 & 13.8 \\
\hline Aluminium & 1.95 & 1.52 \\
\hline Magnesium & 0.988 & 0.046 \\
\hline Barium & 0.599 & 0.043 \\
\hline Strontium & 0.143 & 2.09 \\
\hline Potassium & 4.98 & 2.09 \\
\hline Sodium & 40.5 & 2.88 \\
\hline Calcium & 17.4 & 2.22 \\
\hline Titanium & 4.63 & 0.026 \\
\hline Chromium & 0.154 & 0.072 \\
\hline Manganese & 0.394 & 5.25 \\
\hline Ferum & 20.5 & 0.037 \\
\hline Cobalt & 0.136 & 0.007 \\
\hline Zinc & 0.038 & 0.003 \\
\hline Lead & 0.036 & 0.003 \\
\hline Copper & 0.003 & \\
\hline
\end{tabular}

Table 1: XRF analysis of raw Jourdiqua and $50 \% \mathrm{HCl} /$ Clay.

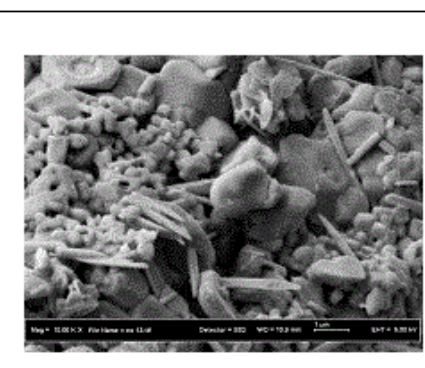

(a)

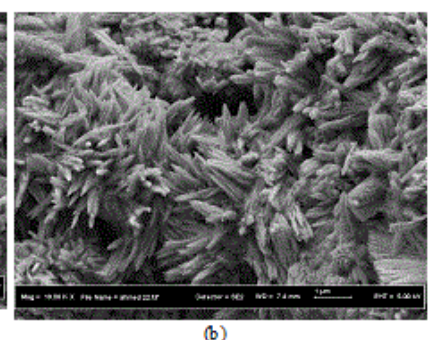

Figure 4: FESEM image magnified $10 \mathrm{KX}$, for raw Jourdiqua .

\section{$\mathrm{X}$-ray fluorescence (XRF) analysis}

This technique was used to determine the elemental analysis of raw and modified $50 \% \mathrm{HCl} /$ clay. The results are shown in Table 1 . Raw Jourdiqua clay has a higher amount of silica (6.030\%) compared to alumina $(1.950 \%)$ and the ratio of silica to alumina $\mathrm{SiO} 2 / \mathrm{Al} 2 \mathrm{O} 3$ is greater than unity which make it suitable for zeolites synthesis [7]. Other cations present in the raw Jourdiqua clay can be replaced by ion exchange process with desired cations leading to higher catalytic activity. Modified $50 \% \mathrm{HCl} /$ clay resulted in increase in $\mathrm{Si}$ and $\mathrm{Al}$ percentage with respect to other cations from $6.03 \%$ to $69.5 \%$ and $1.9 \%$ to $13.8 \%$, respectively. Other cations decreased, because of the removal from the exchangeable sites of the clay [8]. 
Page 4 of 5

\section{X-ray diffraction $(\mathrm{XRD})$ analysis}

$\mathrm{X}$-ray diffractogram of raw Jourdiqua clay and that modified $50 \%$ $\mathrm{HCl} /$ clay are illustrated in Figures 5, 6 respectively. It is found that raw Jourdiqua clay shows peaks at $2 \theta$ of $21.00(4.12 \AA), 26.66(3.33 \AA)$ and 28.00 (3.19 Å) corresponding to [ $\left[\begin{array}{lll}1 & 1 & 0\end{array}\right],\left[\begin{array}{lll}6 & 0 & 0\end{array}\right]$ and $\left[\begin{array}{lll}1 & 1 & 1\end{array}\right]$ planes, respectively. This indicates the presence of montmorillonite, (JCPDS, pdf card No, 00-154-5943). The peaks at $2 \theta$ values of 20.00 (4.20 $)$, $26.66(3.33 \AA)$ and $36.50(2.475 \AA)$ corresponds to the planes of [ $\left[\begin{array}{lll}1 & 1 & 1\end{array}\right]$, $\left[\begin{array}{lll}1 & 2 & 0\end{array}\right]$ and $\left[\begin{array}{lll}1 & 1 & 2\end{array}\right]$ respectively. This indicates the presence of muscovite, (JCPDS, pdf card No, 00-010-4986). While peaks at $2 \theta$ of 26.66 (3.34 $\AA$ ), 50.00 (1.816 $\AA$ ), and 60.00 (1.514 $\AA$ ), corresponding to the planes of 006,112 and 211 , indicating the presence of quartz, (JCPDS, pdf, card No, 00-210-3487). The main clay minerals in Jourdiqua clay are montmorillonite, muscovite and quartz [9].

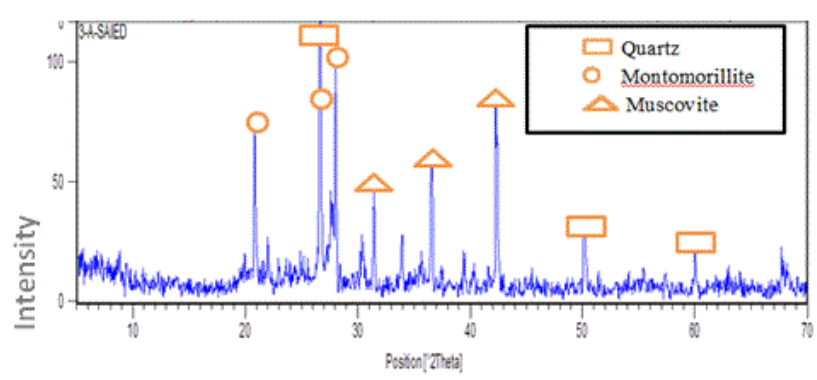

Figure 5: XRD spectrum of raw Jourdiqua clay.

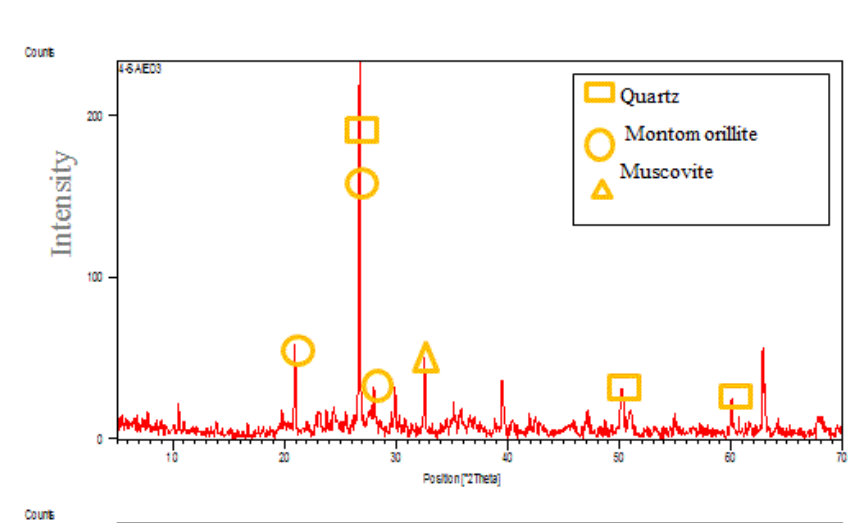

Figure 6: $\mathrm{XRD}$ spectrum of $50 \% \mathrm{HCl}$ modified clay.

After acid modification under the optimum conditions, XRD spectrum of $50 \% \mathrm{HCl}$ modified clay shows decreasing in intensity for the peaks at $2 \theta$ of $21.00(4.12 \AA)$, plane of 110 , and at $2 \theta$ of 28.22 (d) spacing of $(3.19 \AA)$ plane of $1 \quad 1 \quad 1$, which were related to montmorillonite mineral. This is due to the removal of octahedral sheet cation, and further leaching of acid and heat leading to the decrease in mineral crystallinity. The peaks of muscovite at $2 \theta$ of $20.00^{\circ}$, and $36.50^{\circ}$ relate the planes, of 111 and 211 show greater decrease in intensities. While the peak at $2 \theta 26.66^{\circ}$ related to plane of 6 00 which belong to the quartz mineral shows considerable increase intensity. Other peaks show decrease in their intensities due to the removal of cations from octahedral sheets, resulted from the effect of acid.

\section{Nitrogen adsorption analysis}

The porosities of raw Jourdiqua clay and acid modified clay were determined by nitrogen adsorption/desorption analysis of BET adsorption measurements. From the nitrogen adsorption/desorption isotherm of raw Jourdiqua and $50 \% \mathrm{HCl} /$ clay that are, shown in Figure 7. Both catalysts exhibit type IV isotherm, which was related to mesoporous pore and this is confirmed by determination of pore diameter from BET analysis as is shown in Table 2. The two catalysts follow H3 hysteresis loop which is characterized by, unlimited adsorption at high relative pressure of P/Po. [10].

\begin{tabular}{|l|l|l|}
\hline Parameters & Raw Jourdiqua clay & $\mathbf{5 0 \%}$ HCl/acid \\
\hline BET surface area $(\mathrm{m} 2 / \mathrm{g})$ & 4.5835 & 59.87 \\
\hline BET surface area of pores $(\mathrm{m} 2 / \mathrm{g})$ & 5.833 & 2.893 \\
\hline t-plot external surface area $(\mathrm{m} 2 / \mathrm{g})$ & 3.8414 & 56.967 \\
\hline Pore volume cm3/g & 0.0337 & 0.13842 \\
\hline BET average diameter $\AA$ & 335.5 & 92.481 \\
\hline BJH average diameter desorption $\AA$ & 199.37 & 88.618 \\
\hline
\end{tabular}

Table 2: Textural properties of raw Jourdiqua clay and 50\% $\mathrm{HCl} /$ clay.

After acid modification, increase in both surface area and pores volume was observed, due to the removal of silica and alumina caused by the acid. The two catalysts have complex pore structure, formed from interconnected networks of pores with different sizes and shapes, which are common to many inorganic oxides gels, zeolites and clays, normally indicates the presence of mesoporous with ink-bottle pores [11].

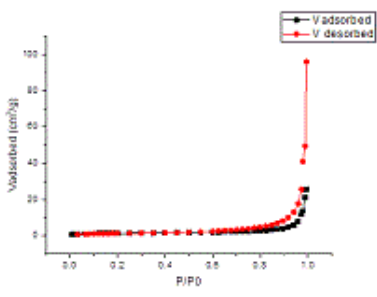

(a)

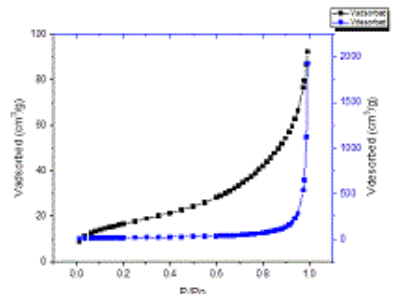

(b)
Figure 7: N2 Adsorption-desorption isotherm for raw Jourdiqua clay.

\section{Biodiesel production}

Biodiesel was prepared in transesterification reaction of castor oil with methanol using raw Jourdiqua clay and acid modified Jourdiqua clay as heterogeneous catalysts. Figure 8 summarize the percentage conversion of transesterification reaction between castor oil and methanol in the presence of heterogeneous raw and acid modified Jourdiqua clay [12]. Raw Jourdiqua clay has a $\mathrm{pH}$ value of 11.30, indicating that the clay is basic. Transesterification reaction using raw Jourdiqua clay gave a conversion of $64.99 \%$. Jourdiqua clay modified by $\mathrm{HCl}$ with different percentage of acid to clay at $30 \%, 40 \%, 50 \%, 60 \%$ and $70 \%$ concentration resulted in ion exchange process between 
Citation: Yacob AR, Mohmedahmed AMS, Azam bin M, Zaki M (2017) Acid Modified Jourdiqua Clay for Methanolysis of Castor Oil. J

Page 5 of 5

protons of $\mathrm{HCl}$ and cations present in exchangeable region between the clay layers. As the acid concentration increases, the conversion of oil to biodiesel increased, the biodiesel conversion was found to be as follows: $17.94 \%, 57.86 \%, 83.86 \%, 64.93 \%$ and $29.34 \%$ conversion for $30 \%, 40 \%, 50 \%, 60 \%$ and $70 \%$, respectively.

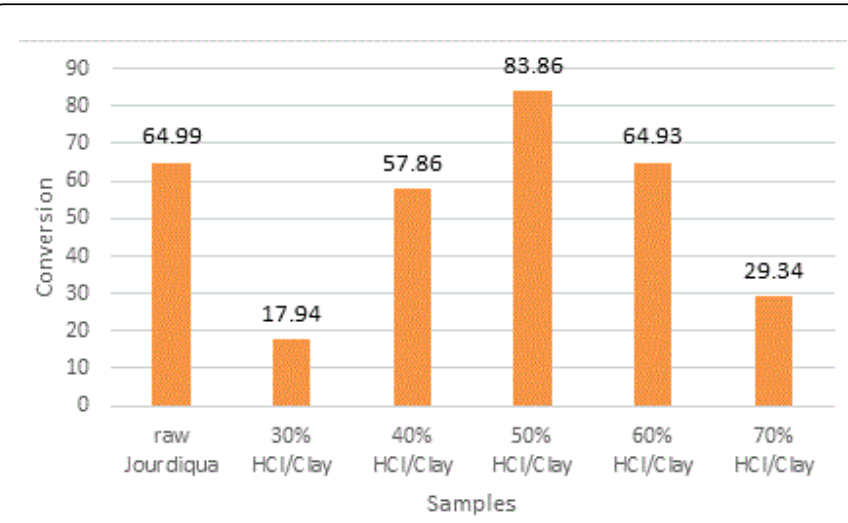

Figure 8: Percentage conversion of biodiesel for acid modified clay.

This is due to the increase of the catalytic activity in the modified clay. However, further increase of acid in the modified clay result in lower conversion yield. Beyond 50\% concentration of $\mathrm{HCl}$, the conversion decreased to $64.93 \%$ and $29.34 \%$ for $60 \% \mathrm{HCl} / \mathrm{Clay}$ and $70 \% \mathrm{HCl} / \mathrm{Clay}$ respectively. This is due to the formation of silanol groups between clay layers, and decreasing of catalytic activity [5].

\section{Conclusion}

The prepared acid modified Jourdiqua clay was identified and could be an effective and potential heterogeneous acid catalyst in transesterification of castor oil to biodiesel. The effect of structure and modification of the clay by acid were evaluated on the conversion of oil to biodiesel. Transesterification process showed a promising conversion yield due to the improvement of the clay catalytic activity after the modification with acids. The percentage conversion of biodiesel for $30 \% \mathrm{HCl} /$ Clay, $40 \% \mathrm{HCl} / \mathrm{Clay}, 50 \% \mathrm{HCl} / \mathrm{Clay}, 60 \% \mathrm{HCl} /$ Clay and $70 \% \mathrm{HCl} /$ Clay were $17.94 \%, 57.86 \%, 83.86 \%, 64.93 \%$, and $29.34 \%$ respectively. Highest percentage conversion was obtained from $50 \% \mathrm{HCl} / \mathrm{Clay}$. This showed that, the conversion of methyl ester in biodiesel depends on the concentration and the strength of the acid catalytic sites of the prepared modified clay. However, higher percentage loading of $\mathrm{HCl}$ will eventually decreased the conversion yield. Thus, the optimum concentration of $\mathrm{HCl}$ for the clay modification is $50 \% \mathrm{HCl} /$ Clay.

\section{Acknowledgement}

Special thanks to University Teknologi Malaysia (UTM) for financial support in this research.

\section{References}

1. Guerrero FCA, Guerrero-romero A, Sierra FE (2010) Biodiesel production from waste cooking oil. Biodiesel-Feedstocks and Processing Technologies 7: 23.

2. Azzouz A, Nistor D, Miron D, Ursu AV, Sajin T, et al. (2006) Assessment of acid-base strength distribution of ion-exchanged montmorillonites through NH3 and CO2-TPD measurements. Thermochimica Acta 449: 27-34.

3. Garcia MJ, Prieto F (2012) Obtaining and characterization of biodiesel from castor oil (Ricinus communis) and sunflower (Helianthus annuus) grown in tabasco mexico. IJAST 2: 58-74.

4. Pratap SR, Shamshuddin SZM, Thimmaraju N, Shyamsundar M, Reena SS (2015) Kinetics of transesterification of Madhuca Indica oil over

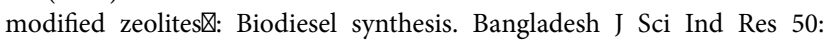
271-278

5. Apita AO, Temu AK (2013) Castor Oil Transesterification Reaction Kinetics for Biodiesel Production. IJSER 4: 1-5.

6. Belchinskaya L, Novikova L, Khokhlov V, Tkhi JL (2013) Contribution of ion-exchange and non-ion-exchange reactions to sorption of ammonium ions by natural and activated aluminosilicate sorbent. Journal of Applied Chemistry 2013: 1-9.

7. Ahmed SA, Tantawy MA, Abdallah EM, Qassim MI (2015) Characterization and application of kaolinite clay as solid phase extractor for removal of copper ions from environmental water samples. IJAR 3: 1-2

8. Ravichandran J, Sivasankar B (1997) Properties and catalytic activity of acid-modified montmorillonite and vermiculite. Clays and Clay Minerals 45: $854-858$

9. Naumov S (2009) Hysteresis Phenomena in Mesoporous Materials. 95.

10. Albuquerque MCG, Jimenez-Urbistondo I, Santamaria-Gonzalez J, Merida-Robles JM, Moreno-Tost R, et al.(2008) $\mathrm{CaO}$ supported on mesoporous silicas as basic catalysts for transesterification reactions. Applied Catalysis A: General 334: 35-43.

11. Reddy CR, Bhat YS, Nagendrappa G, Jai Prakash BS (2009) Bronsted and Lewis acidity of modified montmorillonite clay catalysts determined by FT-IR spectroscopy. Catalysis Today 141: 157-160.

12. Jackson M, Mantsch HH (2008) The use and misuse of ftir spectroscopy in the determination of protein structure. Crit Rev Biochem Mol Biol 30: 95-120. 